\title{
Pyoderma gangrenosum following reduction mammaplasty
}

\author{
Amy M Simon MD ${ }^{1}$, Dana Khuthaila MD FRCSC ${ }^{1}$, Dennis C Hammond MD ${ }^{1}$, Albert Andres MD²
}

\begin{abstract}
AM Simon, D Khuthaila, DC Hammond, A Andres. Pyoderma gangrenosum following reduction mammaplasty. Can J Plast Surg 2006;14(1):37-40.

The failure of a postoperative local infection to resolve after appropriate antibiotic therapy should prompt consideration of other diagnoses. Reported here is a case of pyoderma gangrenosum, a rare necrotizing disorder, occurring after reduction mammaplasty. The clinical presentation was one of progressive wound deterioration with associated erythema and intense pain. After failure of antibiotic therapy and local wound care, tissue biopsy of the enlarging wound edge confirmed the diagnosis, which then responded rapidly to systemic steroid treatment. Given that the treatment for pyoderma gangrenosum is at odds with the standard treatment for an infection (steroids versus antibiotics), differentiating between the two diagnoses is vital to providing resolution of the process and limiting any untoward scarring resulting from the advancing open wounds that can develop. With this in mind, the physical signs and symptoms that characterize this condition and thus allow early diagnosis are presented, and treatment options discussed.
\end{abstract}

\section{Apparition d'idiophagédénisme après une plastie mammaire de réduction}

\begin{abstract}
La résistance d'une infection locale postopératoire à un traitement antibiotique approprié devrait susciter la recherche d'autres diagnostics. Voici un cas d'idiophagédénisme (pyoderma gangrenosum), affection nécrotique rare, qui est apparu à la suite d'une plastie mammaire de réduction. Une détérioration progressive de la plaie, associée à de l'érythème et à une forte douleur composait le tableau clinique. Une biopsie tissulaire du bord extensif de la plaie, effectuée après l'échec du traitement antibiotique et desoins locaux d'entretien a confirmé le diagnostic d'idiophagédénisme, qui a réagi rapidement à un traitement aux stéroïdes à action générale. Comme le traitement de cette dernière affection s'oppose au traitement habituel des infections (stéroïdes par rapport aux antibiotiques), il est d'une importance capitale de différencier les deux diagnostics afin, d'une part, de mettre fin au processus évolutif et, d'autre part, de limiter la formation de tissu cicatriciel par suite de l'envahissement des plaies ouvertes. Il sera donc question, dans le présent article, des signes et symptômes physiques qui caractérisent l'affection en vue d'en faciliter le diagnostic précoce ainsi que des différents traitements possibles.
\end{abstract}

Key Words: Pyoderma gangrenosum; Reduction mammaplasty; SPAIR

\section{CASE PRESENTATION}

A 35-year-old woman presented for bilateral reduction mammaplasty (Figure 1). Her medical history was significant for eczema and a previous diagnosis of ulcerative colitis which was quiescent. Preoperative laboratory studies were normal with the exception of a mild eosinophilia of $0.77 \%$ (normal range $0 \%$ to $0.45 \%$ ). A bilateral short scar periareolar inferior pedicle reduction (SPAIR) mammaplasty was performed in a standard fashion removing $490 \mathrm{~g}$ of tissue from the right breast and $540 \mathrm{~g}$ from the left $(1-4)$. The patient was discharged home in good condition on postoperative day 1 and was maintained on a course of prophylactic oral antibiotics. The immediate postoperative course was uneventful and the early appearance of the breasts demonstrated a pleasing contour (Figure 2). Subsequently the patient presented to the office with a $2 \mathrm{~mm}$ incision separation at the six o'clock position on the right areola. There was no erythema, tenderness, warmth or purulent drainage. The wound was sutured closed in the office. Four days later she returned with a $3 \mathrm{~mm}$ opening in the same area. Again, there was no sign of infection. The wound was managed conservatively and healed uneventfully. Two weeks later, the patient developed a pinpoint opening at the medial aspect of the nipple areola complex of her left breast. There was a surrounding area of erythema but no evidence of an underlying abscess. Local wound care was initiated and the patient was started on amoxicillin and clavulinic acid. Cultures grew Staphylococcus aureus with multiresistant patterns. Based on culture sensitivities, the antibiotic was eventually switched to tetracycline $500 \mathrm{mg}$ four times a day. Within $48 \mathrm{~h}$, the cellulitis appeared to be resolving. However, over the next two weeks, the wound progressed markedly, eventually developing into to a $10 \mathrm{~cm} \times 5 \mathrm{~cm}$ ulcer along the inferomedial aspect of the left breast. There was no fever, erythema or purulent drainage. In fact, the wound remained remarkably clean, without induration, and with a granulating bed. There was, however, an odd purple discolouration of the skin edges that became scalloped and slightly undermined in appearance as the wound expanded (Figure 3). The wound was noted to be exquisitely tender, and the patient was subsequently admitted to the hospital. Consultations from dermatology and infectious disease colleagues were requested to aid in the care of the patient. Cultures for aerobes, anaerobes, fungi and acid-fast bacilli were all negative. After several days of intravenous vancomycin, no change was noted. A diagnosis of pyoderma gangrenosum was postulated, and a tissue biopsy was obtained which revealed ulcerated skin with acute and chronic granulomatous necrotizing inflammation classic of pyoderma 


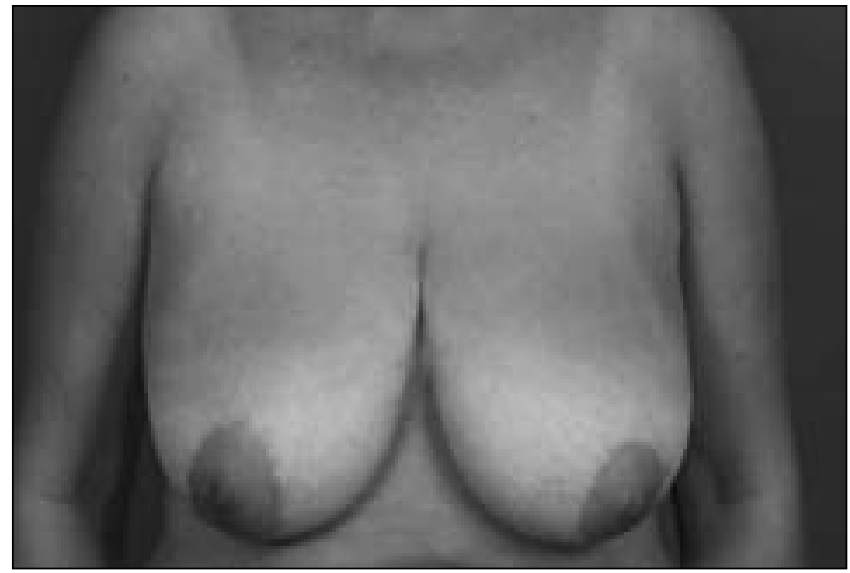

Figure 1) Preoperative appearance of a 35-year-old patient presenting for reduction mammaplasty

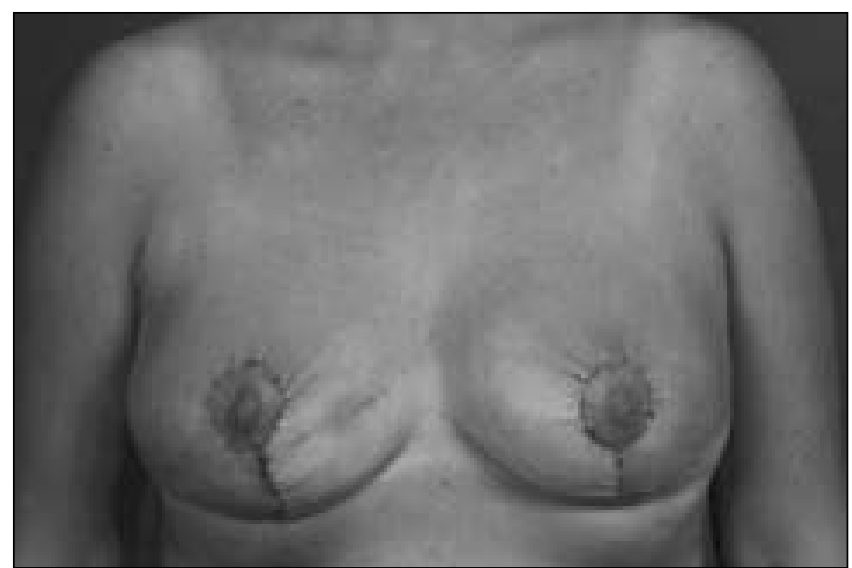

Figure 2) Postoperative appearance at ten days after the removal of $490 \mathrm{~g}$ of tissue from the right breast and $540 \mathrm{~g}$ of tissue from the left

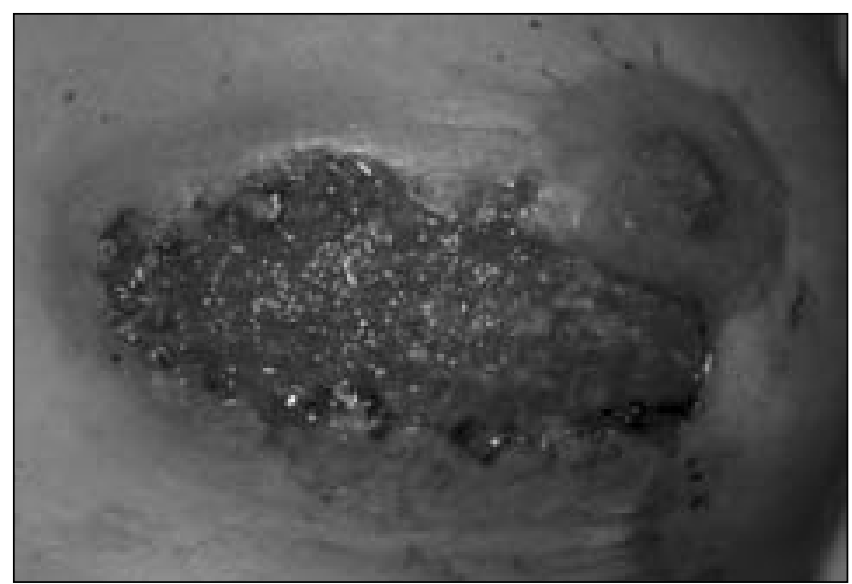

Figure 3) Appearance of the left breast ulcer five weeks after the initial surgery. The wound edges were slightly undermined and had a mottled appearance with a purplish hemorrhagic discoloration. The wound was exquisitely painful

gangrenosum. During the patient's hospital course, other scars on the breasts began to break down. She also developed ulcerations on her tongue (Figure 4). A presumptive diagnosis of pyoderma gangrenosum was made and high-dose oral prednisone therapy (60 mg per day) was begun. All antibiotic therapy was discontinued. Within $48 \mathrm{~h}$, the progression of the expanding wound was halted and the breast wounds and oral lesions began

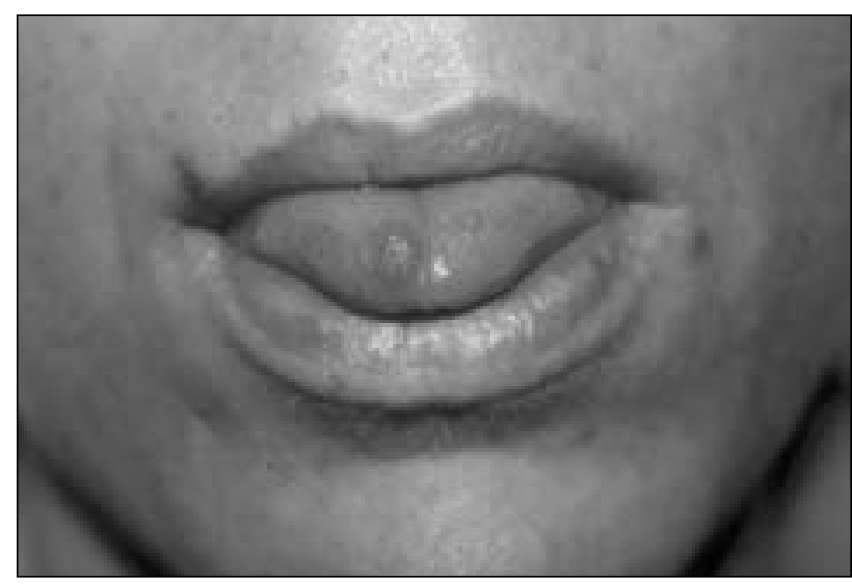

Figure 4) Appearance of a punctuate ulcer on the tip of the tongue

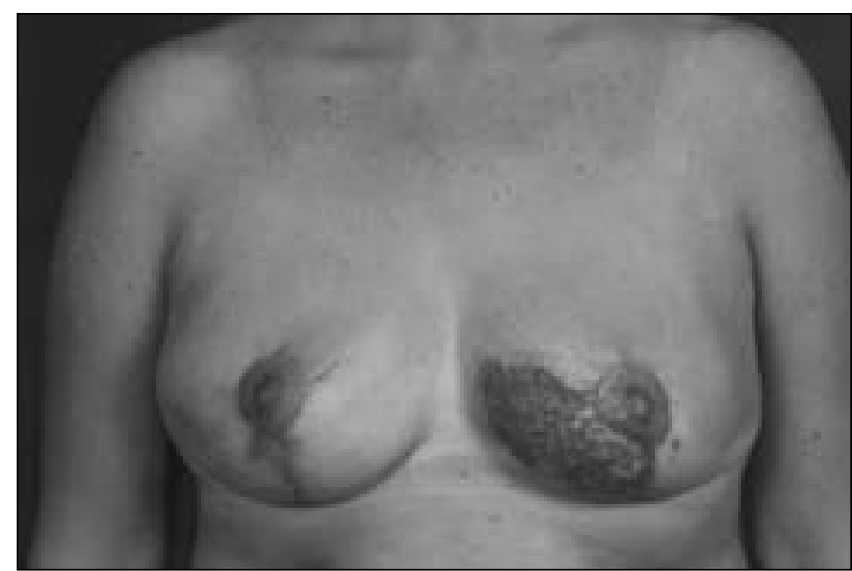

Figure 5) Appearance of the breast wound one week after beginning oral prednisone therapy, and nine weeks after the initial breast reduction

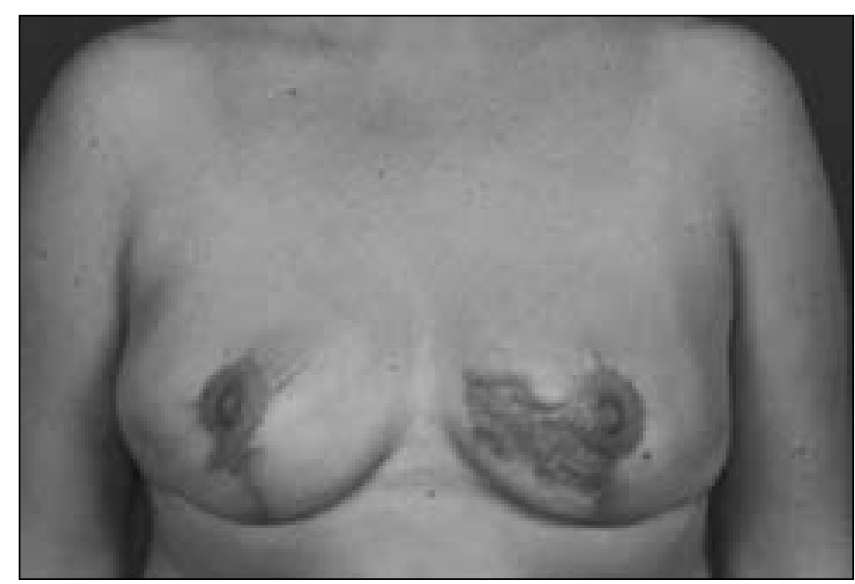

Figure 6) Appearance of the breasts 13 weeks postoperatively shows that the left breast wound is epithelializing and beginning to contract

to heal. The patient was subsequently discharged on an oral prednisone course tapered over time, and her left breast healed completely by secondary intention (Figures 5 and 6). After complete wound maturation, the resulting breast scar was surprisingly inconspicuous and, six years postoperatively, the breast had an aesthetic appearance with no obvious distortion despite the significant size of the original wound (Figure 7). 


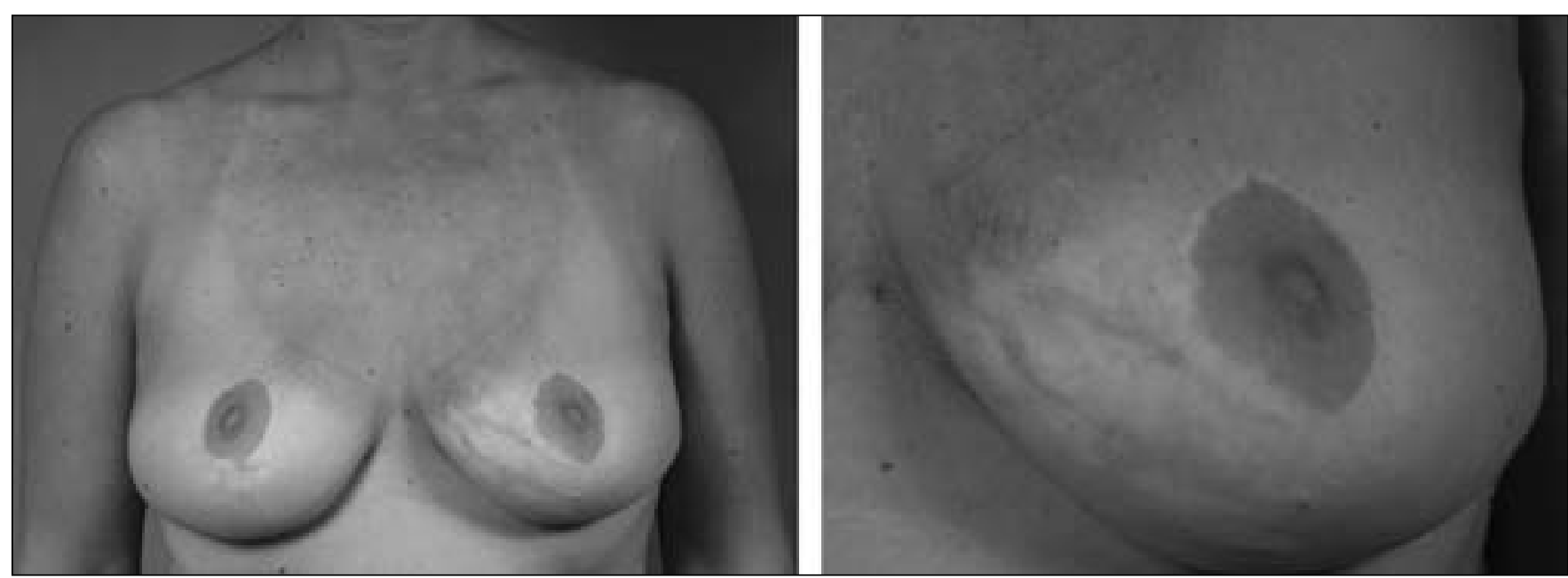

Figure 7) Appearance of the breasts six years postoperatively shows an aesthetic result with only minimal distortion of the breast contour and an inconspicuous scar along the inferomedial portion of the left breast

\section{DISCUSSION}

Pyoderma gangrenosum was originally cited more than 70 years ago when an unusual, necrotizing ulceration of the skin was seen in five patients $(5,6)$. This skin disorder was termed 'pyoderma gangrenosum' because the authors believed that streptococcal infection was the culprit that led to the spreading of this focal lesion, resulting in gangrene. Although this was later found not to be the true cause, the name was retained as the diagnostic terminology.

Pyoderma gangrenosum is a rare, noninfectious, necrotizing cutaneous disorder characterized by exquisitely painful skin lesions with rapidly progressing necrosis. The presentation may be an open wound with a fibrinopurulent base. Lesions often localize at sites of minor trauma.

In a patient who has recently had surgery, the signs and symptoms mimic a postoperative infection. However, antimicrobial therapy fails and cultures of the wound are usually negative. Often, the similarity to an infectious etiology delays the diagnosis of pyoderma gangrenosum. Fully $60 \%$ to $80 \%$ of patients with pyoderma gangrenosum present with a history of other inflammatory disorders, with inflammatory bowel disease being the most common. Other associated disorders include polyarthritis, monoclonal gammopathy, HIV infection and malignant hematological neoplasms, such as leukemia and hypothyroidism $(7,8)$. A differential diagnosis should include progressive synergistic gangrene, ecthyma gangrenosum, clostridial infection, atypical mycobacterial infection, systemic vasculitis, Sweet's syndrome, granulomatous disorders and stasis ulceration. Although the most common site of occurrence is in the lower extremities, there are several case reports of pyoderma gangrenosum following breast surgery (9-18).

The treatment of pyoderma gangrenosum should begin with local wound care and pain management, and continue with specific therapy for the underlying disorder. Systemic corticosteroid therapy has been used with great success and is considered the mainstay of therapy. Other effective regimens include cyclosporine and other immunosuppressants, sulfa drugs, various antimicrobials and topical nicotine. Experimental treatments include intravenous immunoglobulin and hyperbaric oxygen (19).

Historically, wound debridement and skin grafting were presumed to further the progression of skin lesions and even lead to focal lesions at the donor sites. Therefore, operative therapy is best avoided. Other adjuvants include preparation of the wound bed with hyperbaric oxygen or the use of allografts, which offer the added benefit of pain relief $(8,18-27)$. Cultured autografts have also been successful $(28,29)$

Pyoderma gangrenosum is concerning in a surgical setting because of the tendency to misdiagnose it as a postoperative infection. While the physician employs antibiotic treatment, the disease insidiously causes rapid and devastating soft tissue damage. This is especially distressing in breast surgery, in which the aesthetic criteria leave little room for error. A rapidly expanding breast wound presents a serious compromise to the final result, with a delay in diagnosis only compounding the problem.

The key to timely and effective therapy for pyoderma gangrenosum is a high index of suspicion. In the preoperative setting, a careful medical history can identify patients at risk. Any patient with a history of ulcerative colitis, polyarthritis or other chronic inflammatory disorders should be approached with caution.

Postoperatively, be particularly wary of any wound that causes the patient extreme pain out of proportion to the lesion, any wound with edges that have a purple colour and appear slightly undermined, or any wound that fails to respond to appropriate antibiotic therapy. Aggressive medical therapy should also accompany any surgical intervention $(19,24,25,30,31)$.

\section{SUMMARY}

When pyoderma gangrenosum develops after breast surgery, the sequelae of the subsequent open wound can be significant because the breast does not easily tolerate an expanding wound without compromising the ultimate result. A high index of suspicion is the key to timely and effective therapy for this disease. Any patient with a history of chronic inflammatory disorder should be approached with caution. A wound that causes the patient extreme pain out of proportion to the lesion is highly suspect. Wound edges with a purple color, a wound that fails to respond to antibiotics, or any unusual presentation should prompt consideration of this diagnosis. Aggressive medical therapy should accompany any surgical intervention. 


\section{REFERENCES}

1. Hammond DC. The SPAIR mammaplasty. Clin Plast Surg 2002;29:411-21.

2. Hammond DC. Short scar periareolar inferior pedicle reduction (SPAIR) mammaplasty. Plast Reconstr Surg 1999;103:890-901.

3. Hammond DC. Short scar periareolar inferior pedicle reduction (SPAIR) mammaplasty. Op Tech Plast Reconstr Surg 1999;6:106-18.

4. Hammond DC. Short scar periareolar inferior pedicle reduction (SPAIR) mammaplasty/mastopexy: How I do it step by step. Perspect Plast Surg 2001;15:61-70.

5. Brocq L. Nouvelle contribution a l'etude du phagedenisme geometrique. Ann Dermatol Syph 1916;6:1-39.

6. Brunsting LA, Goeckerman WH, O'Leary PA. Pyoderma (ecthyma) gangrenosum: Clinical and experimental observations in five cases occurring in adults. Arch Dermatol Syphilol 1930;22:655-80.

7. Jejurikar SS, Kuzon WM Jr, Cederna PS. Recurrence of pyoderma gangrenosum within a chronic wound following microvascular freetissue transfer. J Reconstr Microsurg 2000;16:535-9.

8. Ma G, Jones G, MacKay G. Pyoderma gangrenosum: A great marauder. Ann Plast Surg 2002;48:546-52.

9. Beurey J, Weber M, Delrous JL, Chaulieu Y. [Pyoderma gangrenosum: Clofazamine therapy.] Ann Derm Venereol 1977;104:631-4.

10. Rand RP, Brown GL, Bostwick J III. Pyoderma gangrenosum and progressive cutaneous ulceration. Ann Plast Surg 1988;20:280-4.

11. Baruch J, Julien M, Touraine R, Auffret P. [Postoperative pyoderma gangrenosum and cancer of the breast. Apropos of a case.] Ann Chir Plast Esthet 1990;35:73-5.

12. Gateley CA, Foster ME. Pyoderma gangrenosum of the breast. Br J Clin Pract 1990;44:713-4.

13. Clugston PA, Thompson RP, Schlappner OL. Pyoderma gangrenosum after reduction mammoplasty. Can J Surg 1991;34:157-61.

14. Grau-Salvat C, Miquel FJ, Pont V, Aliaga A. Pyoderma gangrenosum: Unusual complication following mammoplasty reduction. Int J Dermatol 1998;37:794-6.

15. Sotillo-Gago I, Munoz-Perez MA, Camacho-Martinez F. Pyoderma gangrenosum after augmentation mammoplasty. Acta Derm Venereol $1999 ; 79: 486$.
16. MacKenzie D, Moiemen N, Frame JD. Pyoderma gangrenosum following breast reconstruction. Br J Plast Surg 2000;53:441-3.

17. Shah J, Sharma AK, O'Donoghue JM, Mearns B, Johri A, Thomas V. Necrotising fasciitis of the breast. Br J Plast Surg 2001;54:67-8.

18. Lifchez SD, Larson DL. Pyoderma gangrenosum after reduction mammaplasty in an otherwise healthy patient. Ann Plast Surg 2002;49:410-3.

19. Rozen SM, Nahabedian MY, Manson PN. Management strategies for pyoderma gangrenosum: Case studies and review literature. Ann Plast Surg 2001;47:310-5.

20. Long PI, Uesu CT. Pyoderma gangrenosum. JAMA 1964;187:100-3.

21. Wustrack KO, Zarem HA. Pyoderma gangrenosum: Recognition and management. Plast Reconstr Surg 1978;62:423-8.

22. Davis JC, Landeen JM, Levine RA. Pyoderma gangrenosum: Skin grafting after preparation with hyperbaric oxygen. Plast Reconstr Surg 1987;79:200-7.

23. Dowden RV. Skin grafting of pyoderma gangrenosum lesions. Plast Reconstr Surg 1987;80:648.

24. Long CC, Jessop J, Young M, Holt PJ. Minimizing the risk of postoperative pyoderma gangrenosum. Br J Dermatol 1992;127:45-8.

25. Havlik RJ, Giles PD, Havlik NL. Pyoderma gangrenosum of the breast: Sequential grafting. J Plast Reconstr Surg 1998;101:1909-14.

26. Cliff S, Holden CA, Thomas PRS, Marsden RA, Harland CC. Split skin grafts in the treatment of pyoderma gangrenosum. A report of four cases. Dermatol Surg 1999;25:299-302.

27. Kaddoura IL, Amm C. A rationale for adjuvant surgical intervention in pyoderma gangrenosum. Ann Plast Surg 2001;46:23-8.

28. Dean SJ, Nieber S, Hickerson WL. The use of cultured epithelial autograft in a patient with idiopathic pyoderma gangrenosum. Ann Plast Surg 1991;26:194-5.

29. Limova M, Mauro T. Treatment of pyoderma gangrenosum with cultured keratinocyte autografts. J Dermatol Surg Oncol 1994;20:833-6.

30. Harris AJ, Regan P, Burge S. Early diagnosis of pyoderma gangrenosum is important to prevent disfigurement. BMJ 1998;316:52-3.

31. DesSouza B, Millard R, Flemming S. Pyoderma gangrenosum: Beware, it does recur. Br J Plast Surg 2001;54:82. 